\title{
Impacts of Zoological Garden in Schools (A Case Study of Zoological Garden, Kano State Nigeria)
}

\author{
Azubuike Adams ${ }^{1}$, Azubuike Amarachi Salome ${ }^{2}$ \\ ${ }^{1}$ Biological Science Department, Nigeria Police Academy, Kano, Nigeria \\ ${ }^{2}$ School of Education, Jigawa State College of Education, Gumel, Nigeria \\ Email: ${ }^{\text {dr.azubuikeadams@yahoo.com }}$
}

Received 20 April 2014; revised 20 May 2014; accepted 17 June 2014

Copyright (C) 2014 by authors and Scientific Research Publishing Inc.

This work is licensed under the Creative Commons Attribution International License (CC BY). http://creativecommons.org/licenses/by/4.0/

(c) (i) Open Access

\begin{abstract}
In the course of this work which is the impact of zoological garden in schools, the questionnaire interviewed was used in the collection of data. Based on the finding it was observed that people visit zoological gardens for different purposes like educational, recreational, research, economic and cultural values. Also the chi-square (X2) is used in this research to show if there is significant difference or not. Result indicated that people from various works of life visited the zoo. Some recommendations were also made for further studies as well as the opposition of establishment of a zoo. Thus, the objectives of the this work are to identify the conservation areas in which zoos make a contribution, to develop understanding and support of the conservation potentials of zoos, to convince local zoos and conservation agencies that they can make important contributions to conservation, to help zoos formulate conservation priorities and policies and finally, to promote action of individual zoos by participation in the global zoo and other conservation network.
\end{abstract}

\section{Keywords}

Zoological Garden, Population, Sampling, Respondents

\section{Introduction}

The earliest known zoo was established by Queen Hatshepsut Egypt in about 1500bc. About 500 years later the Chinese emperor Wang founded the garden of intelligence - an enormous zoo that covered about 607 hectares; between 1000 and 400bc rulers from Northern Africa, India and China established many small zoological gar-

"Corresponding author. 
dens. The ancient Greek established public zoo as a place for the study of animals and plant life. Greek students visited for the local zoo as part of their educational purpose. During the Middle Ages, aged monarchs and the mobility liked keeping collection of animals; there was once a collection of lions in the tower of London modern zoo developed from royal managers and from traveling wild beast shows.

By the end of the 1400s global exploration and an increased interest in learning had renewed the desire of Europe arms of zoos. In 1519 spinaches discovered hug zoos built by the Aztec Indians in which is now Mexico. During the next 250 years, a number of zoos were established in Europe. The oldest zoos still in existence are the Schanbrum Zoos that opened in Vienna, Australia. The wildlife has been kept in captivity since almost the beginning of civilization and historically most zoos were started simply for providing public entertainment as only a small fraction of them was started with the idea of promoting scientific studies. The interest of keeping wildlife under captivity has shifted to education and recreation interests. The development of modern scientific zoos as we know today started with the foundation of the zoological society of London which was one of the earliest societies to make serious study of wildlife animal in captivity as its main objective [1].

The zoo animal seldom comes from the wild, because of the adaption of animals' conservation, which produces the vast majority of animals in their collection. Increasingly, today zoos also focus on the reproduction of endangered species such as crane, crocodile, monkeys etc.; zoo scientists devote to improving their reproductive potential of these creatures.

In educational race the Kano Zoo can be seen from the number of individuals, schools, associations and researchers that visited zoo on the basic studies. Primary, science clubs, nursery to university rank the zoo's educational purpose. In zoos people may learn to understand nature and the importance of conservation of wildlife. Presently, natural settings are continually destroyed; this causes a serious education in wild-life population [2].

The first public animal collections opened in major European cities such as Vienna, Paris, Amsterdam, London and Berlin during the late eighteenth and early nineteenth centuries [3]. In most cases, these gardens were established by private zoological scientists that believed their collections would provide scientific interest, natural history instruction and cultural improvement for their cities' growing bourgeoisie.

The zoological society of Philadelphia opening was delayed or postponed because of civil war that occurred within that period, though it was later opened in 1874. The Cincinnati zoological garden debated one year later, drawing its inspiration from the festive animals' parks of Germany. Both institutions embraced the twin goals of instruction and recreation and proclaimed themselves to be civic institutions of the highest order, allied with the libraries, concert halls, museums and other cultural attractions. In most American cities, zoos developed not as philanthropic endeavors but rather as adjusts to municipal parks departments [4].

New York's central park menagerie appeared in the early 1860s, partly as a result of public donations of animals to the city. Chicago's Lincoln Park had its own zoo in 1868, as the first habitant of a pair of swans coming from the central park menagerie. By the end of the nineteenth century, over twenty American cities had opened their own municipal zoos; most of them opened free to the public [5].

The store of zoos which reflected the past, present and future of the animals especially valuable on collecting and display of zoo animals reported that zoo served as an entertainment and educational centre, and people of all ages enjoyed visiting zoos, because of the joy of seeing different species of animals [6]. Zoos provide more than recreation, and they also help keep people aware of the beauties of nature and the need to preserve wild and lectures for schooling children and other groups. In most large zoos, youngsters can pet and perhaps even feed some animals.

On the other hand, zoos served as scientific research, for example, zoologies learned much about animal habit and diseases by studying them in zoos. Studies of animals living in zoo, together with examination of those that have died have provided zoologist with information about the structure and function of animal bodies [7].

Keeping wildlife animals in captivity brings visitors from different parts of the world for different purposes such as to provide sources of recreation in the city, to provide biological specimen, to constitute a learning resources for secondary schools, colleges and universities. It also provides employment and generates revenue.

Wildlife conservation in zoo and game reserve provides sources of protein revenue, esthetics recreation, education and scientific value [8].

The captive animals' propagation is one way of encouraging growth of depleted wildlife species population and so properly planned programme of zoo establishment and development is considered as one of the effective methods for conservation wildlife [9]. 
Educational environment study and the conservation of the environment have become a subject of major importance all over the world, not only from the point of view of preventing pollution, but also from the point of conserving water supplies by protecting water shed, conserving soil, vegetarian and fauna.

Conservation zoos can provide an important facility for research at both pure and applied levels, in both the field and the laboratory in colleges and universities.

According to [10] zoos maintain over 500,000 individuals of terrestrial vertebrates, representing 3000 species of mammals, birds, reptiles and amphibians. [11] emphasized that the primary function of zoo creators is to make the visit a leaving experience.

The attention and effort given to wildlife conservation and tourism in both state and federal levels have been noted.

\subsection{Statement of the Problems}

In the course of carrying out this work, the following problems may be anticipated:

1) Population of animals on the increase;

2) The mortality of animals in the zoo;

3) Visitors usually teasing the animals;

4) Lack of convenience.

\subsection{Study Area Kano Zoo}

Kano Zoo is the largest zoo established in Nigeria; it was officially opened in 1972 by the military governor of Kano State, Alhaji Audu Bako, and it changed to Kano Zoo named for him later.

The entire Kano State occupies an area of 43,000 km lying between 10.30 north and latitude 12.03 north and longitude 8.32 east and is about 1549 feet above the sea level.

The Kano Zoo is located $1 \mathrm{~km}$ Kano Zaria Road, west of Gyadi Quarters. In the immaculately clean and tidy zoological garden, there is a collection of 60 different species and 200 specimens of animals at present.

The zoo is open seven days a week and there is a restaurant with a cool sport to relax. It is strategically located within the garden. They open from 7:30 in the morning to 6:30 in the evening. The gate fee is a hundred naira (Nigeria currency) per adult and fifty naira per child; organized group like associations or clubs may pay in groups or sometimes enter free.

Kano State carries Sudan savannah vegetation which merges in the month of May with $43^{\circ} \mathrm{C}$ and the lowest was recorded in the month of December with $28^{\circ} \mathrm{C}$ [4].

\subsection{Aims of the Study}

This work aims at:

1) The contribution of Kano Zoo in the development of tertiary institutions in Kano State;

2) How a good magnitude of success could be achieved in the work.

\subsection{Hypothesis}

This work assured that:

1) There is a general assumption that zoo entertained the public;

2) It is also assumed that through zoo visit, people understand the nature and the importance of conservation of wildlife.

\section{Materials and Methods}

The purpose of this work is to investigate the impacts of zoological garden in schools.

Area of study:

For the purpose of this work, Kano Zoo is sued as the study area.

\subsection{Population}

The researchers intends to carry out the work in three tertiary institutions in Kano state, institution are: 
- Bayero University Kano (BUK);

- Federal College of Education, Kano;

- Federal College of Education (Technical), Bichi.

\subsection{Data Collection Method}

The instrument used in this work is basically the questionnaire.

\subsection{Sampling}

Data will be collected from a random sampling; various students will be randomly selected from those institutions to make a total number of one hundred students.

\subsection{Development of Instrument}

All the questionnaire items will be developed in line with the purpose of the study. The first three questions of the questionnaire will be personal data of the respondent, while the remaining ones will be aimed to find out the purpose of the work.

\subsection{Administration/Procedure}

The researchers will personally distribute the questionnaire items to the selected students among those three institutes in Kano state and after go back to collect them for analysis.

\subsection{Analysis of Data}

The researchers will use percentage (\%) formula to express in statistical item, the data collected for analysis.

This will be based on the number of respondents to the number of questionnaire distributed item; responses will be produced in table. After scoring and calculations have been completed, the data will be assembled in tabular form to cover all sections to the questionnaire.

\section{Results and Discussion}

This chapter deals with the presentation of result of the study, and the analysis of the respondents for each test items.

The highest number of the respondents are between level one to two students with $27.78 \%$ this was followed by the respondents at level three to four students with $25.00 \%$ while the remedial students has the percentage of $9.26 \%$ which is the least percentage (Table 1 ).

From the analysis of TX 2 test, the result shows a significance difference in the level o studies of the respondents (calculated value $=11.17$, the tabulated $=9.49$ of $\mathrm{X}_{2}$ ) at $5 \%$ significant level.

From F.C.E Kano students response, shows that B.Ed Students has the highest number of respondents with 52 and 50.1 percent, NCE students is the second with 46 and Diploma students are the least with 10 respondents (Table 2).

From FCE (Technical) Bichi shown in the result indicates that NCE II students has the highest percentage of $50.00 \%$ followed by NCE I students with $41.60 \%$ while NCE III students has the least number of their percentage was $9.27 \%$ (Table 3).

Indicates that the males has the highest percentage of 55.56\% respondents to the interview, and the female has $44.44 \%$ respond. Analysis of the data using the X2-test indicated that there was no significant difference between male and female (calculated value $=1.34$, tabulated value $=3.84$ of X2-test) at $5 \%$ significant level (Table 4).

The composition of the visitors by profession in Table 5 indicated that students have the highest percentage of $40.5 \%$ and civil servant has the second percentage at $38.3 \%$. This group are definitely has interest in wildlife conservation because of the nature of their studies and work. Businessmen and self-employed may not have time to visit the zoo.

Using X2 test, the result shows significance difference in the profession of visitors to Kano State Zoo, at 5\% level of significance. 
The Table 6 shows that the zoo has the highest chance for sighting wild animals within the state because national park example Kainjidam, national Dam is too far from Kano and only few people can go there.

Table 7 indicates that zoo really served as an educational center, because none of the respondents says no.

Zoo is an area or a place where living animals were brought and kept for the people to go and observed them, understand their nature, importance and breed them. Zoo plays significance roles as education, research centers, cultures, aspects nature conservation entertainment and economics value.

Table 1. Respondents from BUK.

\begin{tabular}{|c|c|c|c|}
\hline \multicolumn{2}{|c|}{ Level of Respondents } & \multirow{2}{*}{$\begin{array}{c}\text { No of Responses } \\
30\end{array}$} & \multirow{2}{*}{$\begin{array}{c}\text { Percentage } \\
27.27\end{array}$} \\
\hline 1. & 2 & & \\
\hline 2. & 3 & 22 & 20.37 \\
\hline 3. & 4 & 27 & 25.00 \\
\hline 4. & 5 & 19 & 17.59 \\
\hline 5. & Remedial & 10 & 9.26 \\
\hline \multicolumn{2}{|c|}{ Total } & 108 & $100 \%$ \\
\hline
\end{tabular}

Table 2. Respondents from FCE Kano.

\begin{tabular}{ccc}
\hline Level of Responses & No of Responses & Percentage \\
\hline B. Ed Students & 52 & $50.1 \%$ \\
NCE Students & 46 & $42.59 \%$ \\
Diploma & 10 & $9.26 \%$ \\
Total & 108 & $100 \%$ \\
\hline
\end{tabular}

Table 3. Respondents from FCE (T) Bichi.

\begin{tabular}{ccc}
\hline Level of Responses & No of Responses & Percentage \\
\hline NCE 1 Students & 40 & $41 \%$ \\
NCE II Students & 50 & $50.00 \%$ \\
NCE III Students & 18 & $9.27 \%$ \\
Total & 108 & $100 \%$ \\
\hline
\end{tabular}

Table 4. The sex of the despondence.

\begin{tabular}{rcc}
\hline Sex & No of Responses & Percentage \\
\hline Male & 60 & $44.46 \%$ \\
Female & 48 & $44.44 \%$ \\
Total & 108 & $100 \%$ \\
\hline
\end{tabular}

Table 5. The percentage of composition of zoo visitors by profession.

\begin{tabular}{ccc}
\hline Profession & No of Responses & Percentage \\
Students & 72 & $40.5 \%$ \\
Businessmen & 30 & $16.0 \%$ \\
Civil Servant & 69 & $38.3 \%$ \\
Self Employed & 9 & $5.0 \%$ \\
Total & 108 & $100 \%$ \\
\hline
\end{tabular}


Table 6. Show the total number of visitors to Kano Zoo from 2005-2011.

\begin{tabular}{cc}
\hline Years & Number of Visitors \\
\hline $\mathbf{2 0 0 5}$ & 328,900 \\
$\mathbf{2 0 0 6}$ & 90,100 \\
$\mathbf{2 0 0 7}$ & 206,820 \\
$\mathbf{2 0 0 8}$ & 225,000 \\
$\mathbf{2 0 0 9}$ & 171,320 \\
$\mathbf{2 0 1 0}$ & 194,400 \\
$\mathbf{2 0 1 1}$ & 154,700 \\
\hline
\end{tabular}

\begin{tabular}{ccc}
\hline Table 7. Does zoo served as an educational center? & \\
\hline Column & No of Responses & Percentage \\
\hline Yes & 108 & $100 \%$ \\
No & & \\
Total & 50 & $100 \%$ \\
\hline
\end{tabular}

Zoo is a center of entertainment, because people of all ages, students from various institutions enjoyed visiting the zoos. They delighted in viewing creatures of the beauties of nature and the need to preserve wildlife. This agreed with the result obtained in this project, this is because different visitors in the zoo maintained that they are enjoying the zoo, more especially to those who cannot afford to visit the game reserve or parks as shown in the Table 6. So zoological garden contributed a lot by giving people the opportunity to marvel and appreciation of the nature in the condition.

Zoos offer educational tours and lectures fro schooling of different students from various level of education. And it stated that zoo served as a scientific research, example zoological laboratories [5]. There are justified with this project shown in Table 7 and Table 8 because many researchers agreed that zoo is a center of research and various learners (students) learn much about the animals' habits and diseases by studying them in the zoo.

Zoo serve as an entertainment and educational centre, also in the course of this research, that is the contribution of zoological garden to tertiary institutions, the questionnaire interviewed were used in the collection of data, based on the finding, it was observed that zoo is an educational centre (scientific values) [8].

Keeping wildlife animals in captivity brings visitors from outside to see semi natural environment to provide sources of recreation in the city, to provide biological specimen, to constitute a learning resources schools colleges and universities. It is also provides employment and generates revenues, while in this research work it was observed that zoo is an economic value and recreational interest [9].

Wildlife conservation is zoo and game reserve provides sources of protein, revenue, esthetics recreations, education and scientific value but in this research work, it was observed that zoo is a wildlife conservation centre [7].

Primary functions of zoos curators is to make the visit a learning experience while based on the finding, it was observed that zoo is also research centre [11].

It should be noted that based on the result/findings of this project, it was observed that the following were the contributions of zoological garden to tertiary institutions.

As an educational centre (scientific values), research centre, wildlife, conservation, economic value.

The result also indicates that people from various work of life verified the zoo. Some recommendations were also made for further studies as well as guide against the establishment of a zoo.

\section{Conclusions}

It is concluded from the date obtained by this research work that the impact of zoological garden to schools cannot be over emphasized. Also, people/students from various places and institutions enjoyed visiting the zoo for different purposes. These include educational, recreational entertainment, and research; and some are there for economic and cultural values. 
Table 8. Zoo as a research center.

\begin{tabular}{ccc}
\hline Column & No of Responses & Percentage \\
Yes & 34 & $87.18 \%$ \\
No & 5 & $12.82 \%$ \\
Total & 50 & $100 \%$ \\
\hline
\end{tabular}

The most important contribution or function of zoological garden to tertiary institutions is the educational purpose and the center of scientific research; many students want to go there for data collection, when they are carrying out their research project (work), and better results will be obtained.

\section{Recommendations}

In view of what has been observed and studied with the regard to the impact of zoological garden in schools, the research hereby recommends the following:

1) Government should provide adequate facilities for tourism activities, which include items such as badminton, table tennis, snooker game, and swimming pool sties.

2) Creation or establishment of zoo library and a natural museum should be given so that relevant information on art and science related to nature can be displayed in the library.

3) Government should provide services for breeding of endangered species—not only indigenous but also exotic ones.

4) Government should provide adequate fund for research on endangered species.

5) Nongovernmental organization (NGOs) like NCF, IUCN, SPBP, STAN, ETF, PTO etc. should also gear towards the development of zoos especially in the underdeveloped countries like Nigeria.

6) Government should provide effective securities services to the zoo in the case of emergencies for visitors as well as the animal's safety.

7) Public conveniences should be adequately provided for the better entertainment of visitors.

\section{References}

[1] Richard, A.F. (1985) Primate in Nature. Freeman, New York.

[2] Southern, H.N. (1964) The Handbook of British Mammals. Blackwell, Oxford.

[3] Hugo, D. (1872) New Races and Species Origin. McGrasw Hill International Book, London.

[4] Macdonlad, D. (1985) The Encyclopaedia of Mammals I and II. Guild Publishing, London.

[5] Perrins, C.M (1985) The Encyclopaedia of Birds. Allen and Unwin, London.

[6] Croke, V. (1997) The Story of Zoos Past, Present and Failure. Scribes, New York.

[7] Usher, M.B. (1973) Biological Management. Hall, London.

[8] Presley, R. (1984) Lizards, Mammals and Primitive Tetrapod Tympanic Membrane. Symposia of the Zoological Society of London, 52, 127-128.

[9] Okpiri (1990) The World Book Encyclopedia.

[10] Campbell, B. (1985) A Dictionary of Bird. Pyser, Calton.

[11] Bygott, I.D. (1979) Male Lions in Large Coalitions Gain Reproductive Advantage. Nature, 282, 834-835. http://dx.doi.org/10.1038/282839a0 
Scientific Research Publishing (SCIRP) is one of the largest Open Access journal publishers. It is currently publishing more than 200 open access, online, peer-reviewed journals covering a wide range of academic disciplines. SCIRP serves the worldwide academic communities and contributes to the progress and application of science with its publication.

Other selected journals from SCIRP are listed as below. Submit your manuscript to us via either submit@scirp.org or Online Submission Portal.
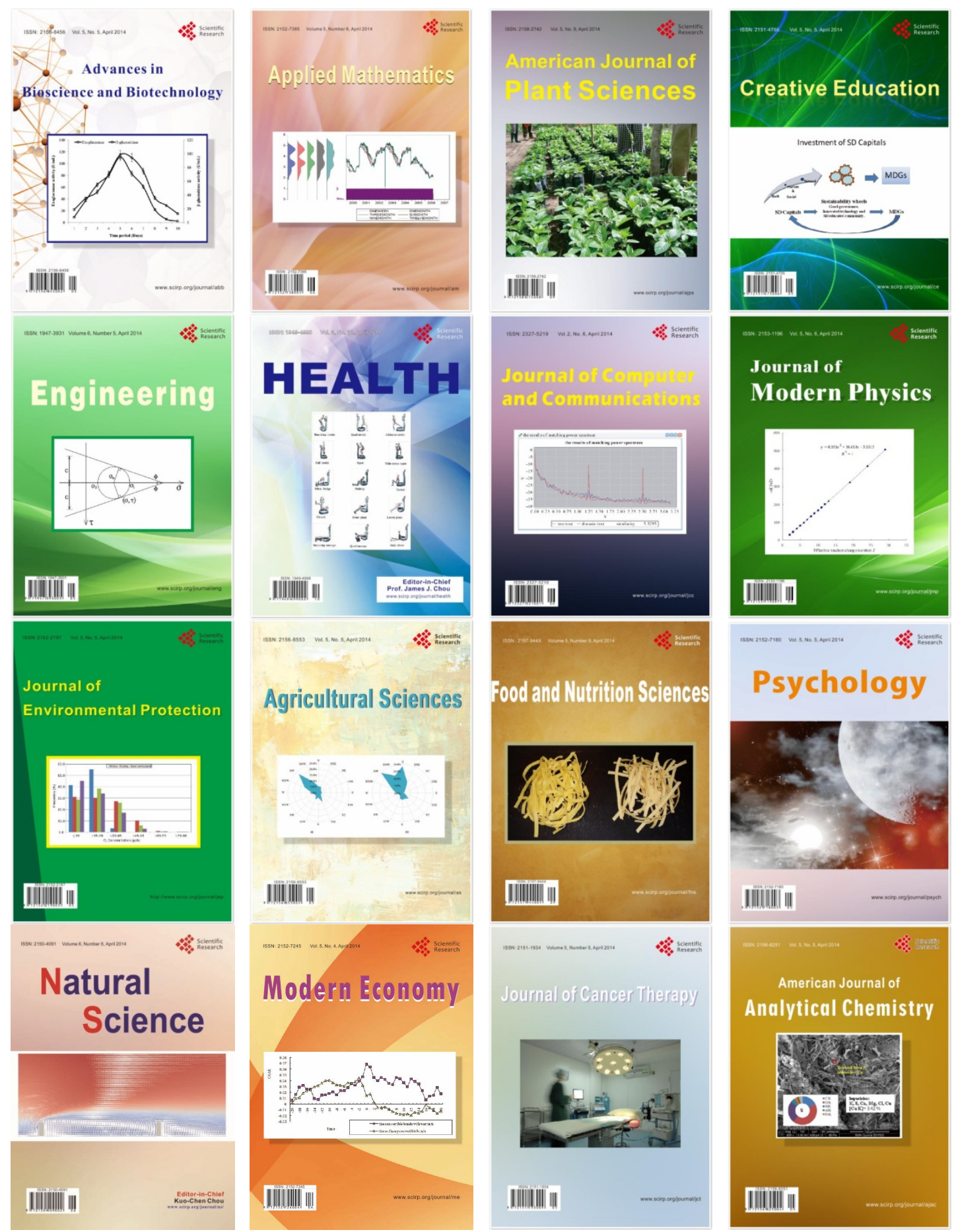